\title{
OS RISCOS E AS VULNERABILIDADES VINCULADAS AOS CATADORES DE LIXO
}

\section{LOS RIESGOS Y LAS VULNERABILIDADES VINCULADA A LOS RECOLECTORES DE BASURA}

\section{THE RISKS AND VULNERABILITIES LINKED TO GARBAGE COLLECTORS}

\author{
Clarice Silva LIMA ${ }^{1}$
}

RESUMO: Este artigo traz uma reflexão sobre os riscos e a vulnerabilidade decorrente da disposição inadequada de resíduos sólidos urbanos. Buscamos mostrar como a má gestão do lixo afeta e ameaça a sociedade em geral e os catadores em particular. A elaboração desta análise foi construída a partir de estudo de caso realizado no aterro controlado de Gericinó, no município do Rio de Janeiro. À luz das informações coletadas em trabalho de campo, proporemos algumas alternativas destinadas pensar a viabilidade da solução dos problemas encontrados.

Palavras-chave: risco urbano, vulnerabilidade, resíduos sólidos, catador.

RESUMEN: Este artículo trae una reflexión sobre los riesgos y la vulnerabilidad derivadas de la disposición inadecuada de los residuos sólidos urbano. Tratamos de mostrar cómo la gestión deficiente de los desechos afecta y amenaza a la sociedad en general y de los recolectores en particular. La elaboración de este análisis se construye a partir del estudio de caso realizado en un terraplén controlado de Gericinó en el municipio de Río de Janeiro. A la luz de la información colectadas en el trabajo de campo, se proponen algunas alternativas para pensar la viabilidad de la solución de los problemas encontrados.

Palabras-clave: riesgo urbano, vulnerabilidad, residuos sólidos, recolector.

\begin{abstract}
This article reflects about the risks and the vulnerability originated by the unappropriated management of urban garbage. We seek to show how it affects the society in general and, specially, those peoples who work and leave in the dumpsites. Our analysis has like reference a study case in the Gericinó landfill, at Rio de Janeiro city. According to information collected in the fieldwork, we propose some alternative ways to solve the problems we have found.
\end{abstract}

Key words: urban risks, social vulnerability, solid waste, garbage collectors.

\footnotetext{
${ }^{1}$ Programa de Pós-Graduação em Geografia (PPGEO). Universidade do Estado do Rio de Janeiro (UERJ). Email: claricecler87@gmail.com
} 


\section{INTRODUÇÃO}

O crescimento demográfico desencadeado desde a década de 60 somado ao desenvolvimento tecno-científico acarretou à sociedade urbana um excessivo consumo e descarte de resíduos, estes muitas vezes ainda com utilidade, no entanto, rejeitados por estarem velhos e antiquados. O lançamento destes no meio ambiente em sua grande parte de forma imprópria faz com que cause graves dificuldades na vida em sociedade, através de problemas sociais e ambientais ${ }^{2}$.

A esses problemas do descarte de resíduos somam-se vários riscos. Quais são estes riscos e que medidas cabíveis podem ser tomadas? Assim, ao longo deste artigo trabalharemos os conceitos de riscos e vulnerabilidades dos resíduos associados aos catadores de lixo de uma área de deposição de resíduos sólidos do município do Rio de Janeiro - Aterro Controlado de Gericinó, mostrando a problemática dos resíduos sólidos no meio urbano que hoje é tido como uma das grandes questões a ser resolvida nas cidades.

\section{Os Riscos dentro do Ambiente Urbano}

Os riscos no ambiente urbano estão relacionados às questões sociais, sua construção, através da interação no espaço que modifica este ambiente gerando impactos ambientais desencadeando em graves implicações para o meio.

Carpi Junior (2001) argumenta que os impactos ou alterações do ambiente passam a se configurar como formas de risco ambiental, que ao ser percebido ou conhecido pelo homem, pode se transformar como ponto de partida para as ações que visem à melhoria da qualidade de vida, juntando esforços dos diversos setores da sociedade.

A gestão do risco evolui com o acúmulo de experiência, que admite uma melhor observação e desencadeamento dos fatos levando a medidas mais concretas que muitas vezes promove um novo posicionamento na estrutura urbana. 


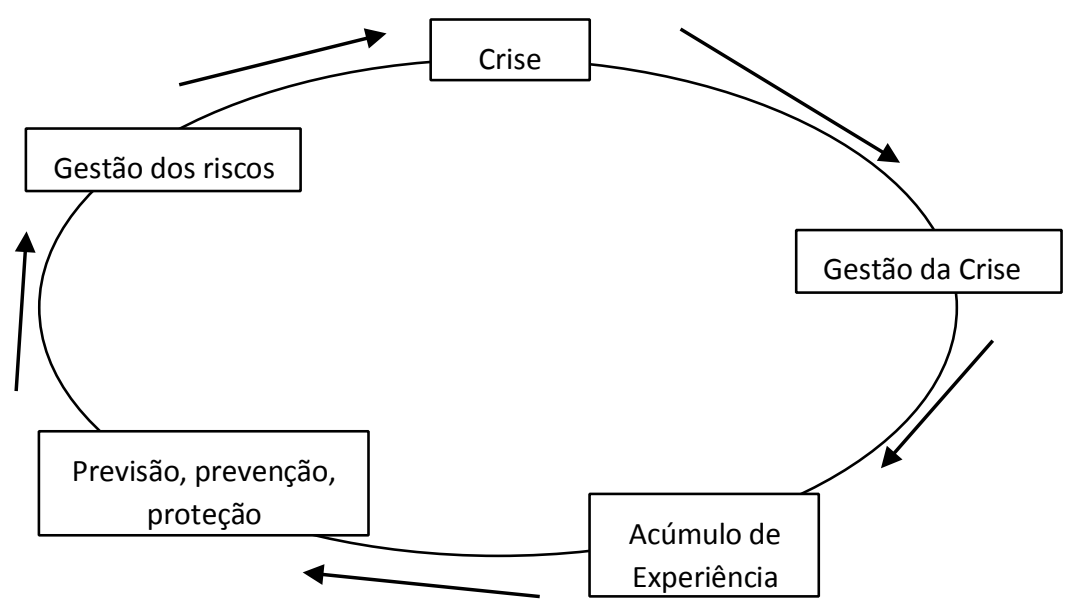

Fig. 1 - As relações entre os riscos e crises. Os ensinamentos do acúmulo de experiência (Fonte: Os riscos - o homem como agressor e vítima do meio ambiente. Yvette Veyret, 2007).

O risco natural é uma designação referente aos riscos não relacionados à ação humana. Rebelo (2003), mostra a seguinte origem dos riscos naturais: riscos tectônicos emagmáticos; riscos climáticos; riscos geomorfológicos; e os riscos hidrológicos. Sobre o risco tecnológico segundo Sevá Filho (1988), está ligado aos processos de produção, de trabalho, e as condições que os funcionários estão expostos.

Os riscos sociais de acordo com Vieillard-Baron (2007), são definidos como os causados por agentes externos, ameaças externas (terremotos, acidentes geomorfológicos, etc.); e os internos gerados pelo modo de vida aderido por uma determinada sociedade. E risco ambiental que é a relação entre riscos naturais mais os riscos sociais causados por meio da intervenção por atividade humana e ocupação do território. Dessa forma, risco ambiental é à possibilidade de haver perda ao ambiente.

Dagnino e Carpi Jr. (2007), diz que o risco se manifesta em condições ou áreas que existe a probabilidade, susceptibilidade, vulnerabilidade, casualidade ou azar de haver um problema, impacto ou desastre. O uso da vulnerabilidade para detectar riscos ambientais enfatiza algo essencial: mostrar os conjuntos humanos e ambientes afetados por acontecimentos nocivos ou potencialmente sujeitos a alguma ameaça.

Estratégia Internacional para Redução de Desastres (UNISDR, 2009), expôs várias considerações de vulnerabilidade que nascem dos fatores físicos, sociais, econômicos e ambientais e que devem ser levados à análise para evitar os riscos como: planejamento incorreto e construção deficiente das edificações, proteção inadequada dos bens materiais, 
defasagem de informações e conscientização pública, limitações na percepção real do risco e dos meios de prevenção, e lapso na gestão ambiental sensata e prudente.

A percepção de vulnerabilidades possibilita compreender as necessidades que está sujeita uma comunidade ou alguns indivíduos, pois o estudo de vulnerabilidade ocorre em diferentes níveis (individual $\mathrm{x}$ social/coletiva) e por diferentes aspectos (social $\mathrm{x}$ socioambiental), Vieillard-Baron (2007). Esta compreensão da situação de riscos/vulnerabilidade às vezes não é percebida pela má divulgação.

CUNHA et al. (2003), na vulnerabilidade social diz que o espaço está dividido em diferentes zonas, apresentando estas carências ou vantagens diferenciadas que depende da zona onde estes grupos sociais estão instalados, que traz diferente conjunto de dificuldades devido a desigualdade dos espaços que são expostos aos habitantes. E a vulnerabilidade socioambiental segundo Hogan et al (2000), traz a relação desta com a questão socioeconômica, pois, esta gera distribuição desigual dos bens e serviços públicos, e as desigualdades socioespaciais que possibilita as diferentes formas de ocupação do espaço.

A segregação cultural e discriminação social por relação à situação econômica das diferentes classes sociais podem ser percebidas pela classe dos catadores de lixo, estes que por falta de estudo não encontraram oportunidades para um trabalho mais digno se sujeitando a viver no lixo, em locais insalubres, realizando atividade precária, correndo risco de vida e de saúde, sendo cidadãos excluídos socialmente. A autora Escorel define exclusão social como:

a exclusão social significa, então, o não encontrar nenhum lugar social, o não pertencimento a nenhum topos social, uma existência limitada à sobrevivência singular e diária. Mas, e ao mesmo tempo, o indivíduo mantem-se prisioneiro do próprio corpo. Não há mais um lugar social para ele, mas deve encontrar formas de suprir suas necessidades vitais e sobreviver sem suportes estáveis materiais e simbólicos. (ESCOREL et al., 2000, p.113)

O modelo de consumo adotado pela sociedade leva ao esgotamento dos recursos naturais, a exacerbação da pobreza baseado no consumo exagerado de poucos e no descarte precoce dos materiais. Os materiais descartáveis, consumidos sem equilíbrio, levam a grande geração de lixo, que frente às políticas econômicas e sociais, faz com que uma massa de excludentes da sociedade, passe a se "beneficiar" dessa geração, que se trata da população de catadores de materiais recicláveis.

Os catadores estão subdivididos em três categorias: catadores de rua, catadores de lixão e catadores cooperados. Catadores de rua são aqueles que adquirem o material reciclável pelos sacos de lixo deixados nas ruas pela população, comércio ou indústria, possuindo o seu 
próprio meio de transporte sendo este normalmente uma carroça. Os catadores dos lixões são aqueles que vivem realizando a catação nas montanhas de lixo geradas pelos municípios não possuindo assistência e organização. E os catadores de cooperativas, organizados realizando a triagem dos materiais pré-selecionados nas residências, comércios ou indústrias.

Para Calderoni (1999), a relação das classes inferiores com os resíduos sempre será a mais precária possível, mesmo que estes tirem desses locais sustentos para sua sobrevivência, estarão vulneráveis a doenças, as condições de vida do resto da população estará comprometido pela proximidade com áreas de deposição além, de estas áreas contribuírem para poluição ambiental.

\section{Deposição de Resíduos no Meio}

Diariamente são descartadas inúmeras toneladas de sobras de alimentos, embalagens, equipamentos eletrônicos, resíduos industriais, entre outros, que se houvesse uma gestão específica, integrada e sustentável, muitos desses seriam reaproveitados sem comprometer o meio ambiente e social.

O volume gerado/descartado de resíduos que aumenta consideravelmente a cada dia devido a uma sociedade estimulada ao consumo/consumismo, lançando no meio objetos que ainda possuem utilidades, aumentando o volume dos aterros, quando não de lixões, deixando o lixo expostos a céu aberto sem nenhum tipo de estudo ou utilização de técnica para o descarte do mesmo.

Quadro agravado pelo modelo urbano-industrial intensivo e predatório que provocou graves mudanças socioespaciais, gerando consequências ambientais muito graves. Sistema que Sobrecarrega principalmente as classes sociais mais humildes que através dos processos de segregação territorial e exclusão socioeconômica habitam áreas mais precárias, com serviços públicos insuficientes; distribuição desigual de equipamentos urbanos e comunitários; falta de áreas verdes; padrões inadequados de uso do solo; e baixa qualidade de técnica de construção, ficando mais vulneráveis aos impactos gerados pelo descarte de resíduos sólidos. (MENDONÇA, 2004).

Rodrigues (2001) traz que sistema produtivo atrelado à produção, circulação e consumo, implantados geram problemas ao meio socioambiental por voltar-se apenas a geração de mercadorias não analisando as consequências advindas por esse processo.

Se pegarmos a linha de pensamento do sociólogo alemão Beck (1986) e fizermos uma associação com o descarte dos resíduos, o risco estaria ligado à crise que estes geram através 
da poluição do ecossistema pela poluição do solo, água, ar e de sua grande degradação em decorrência desta, deixando a população vulnerável a vários riscos.

O lixo espalhado no meio urbano contribui para os agentes transmissores de doenças que sobrevivem e reproduzem pela alimentação desses rejeitos como os ratos, baratas, moscas e mosquitos, podendo contaminar os seres humanos por transmissão direta - por meio de micro-organismos (bactérias, vírus, protozoários e vermes), patogênicos em contato com o lixo, transmitindo doenças aos que manuseiam estes rejeitos; e transmissão indireta estendendo a mais pessoas, advindas pela contaminação do ar, da água, do solo e por vetores de doenças como insetos. (FUNASA, 2013).

O processo de contaminação da água conforme Ribeiro e Lima (2000) ocorrem de forma direta pelo lançar de resíduos nesta fonte indiscriminadamente como destino final, ou através de processos indiretos, como os mecanismos de percolação, precipitação, lixiviação e arrastamento que ocorre por meio do solo e água das chuvas, carregando substâncias poluentes como o chorume, líquido de cor escura advindo da matéria orgânica em decomposição, causando a turbidez do meio, a formação de bancos de lodo ou sedimentos e a alteração na temperatura, dificultando a vida de certas espécies.

Ao referir à poluição do ar originada dos resíduos sólidos urbanos temos, a decomposição dos rejeitos orgânicos dos lixões e aterros liberando o biogás nos seus primeiros meses, formado metade pelo gás metano e a outra metade dividida entre dióxido de carbono, vapores d'água e ácidos. O aumento da geração de biogás depende da quantidade de restos orgânicos, umidade e temperatura da região.

A elevação na produção de rejeitos gera um acréscimo na emissão de gases do efeito estufa (GEE), metano e dióxido de carbono, que promovem o elevado aquecimento do planeta Terra, ocasionando consequências alarmantes para a humanidade além do aumento da temperatura, o descongelamento das geleiras polares, elevando o nível de água dos oceanos, causando inundações em cidades situadas em litoral, além, de alterar a velocidade dos ventos e o regime de chuvas. (LIMA, 1991)

Dentre as formas de disposição final dos resíduos os autores, Borgatto (2010) e Dantas (2008), classificam-os como:

\section{Lixão}

Meio de dispor o lixo sem nenhuma proteção/prevenção ao meio ambiente, avaliado como a pior forma de disposição destes, por causar a poluição do solo e água pelo chorume (líquido proveniente pela decomposição de compostos orgânicos), emitir gases poluentes e 
cheiro desagradável, veículo de transmissores de doenças, além, de não realizar controle do acesso de pessoas e animais nos mesmos.

\section{Aterro Controlado}

O fator diferencial dos aterros com os lixões é o fato de esses apresentarem um controle mínimo na cobertura do solo, uma compactação dos resíduos diminuindo o volume destes e um maior controle no acesso de pessoas e animais.

\section{$\underline{\text { Aterro Sanitário }}$}

No aterro sanitário para alojar o resíduo há princípios de engenharias juntamente com normas específicas, havendo uma preocupação com o controle da poluição ambiental e cuidados à saúde da população. São elaborados por células de disposição, compactação de resíduos, cobertura, sistema de drenagem, captação do chorume e gases produzidos com tratamento do chorume e utilização dos gases na produção de energia, e monitoramento contínuo do local.

Para uma visão geral da destinação final dos resíduos sólidos no país a Associação Brasileira de Empresas de Limpeza Pública e Resíduos Especiais - ABRELPE realizou um levantamento da quantidade depositada diariamente nos três tipos de deposição, entre os anos 2011 e 2012.Como mostrado na Figura 2.

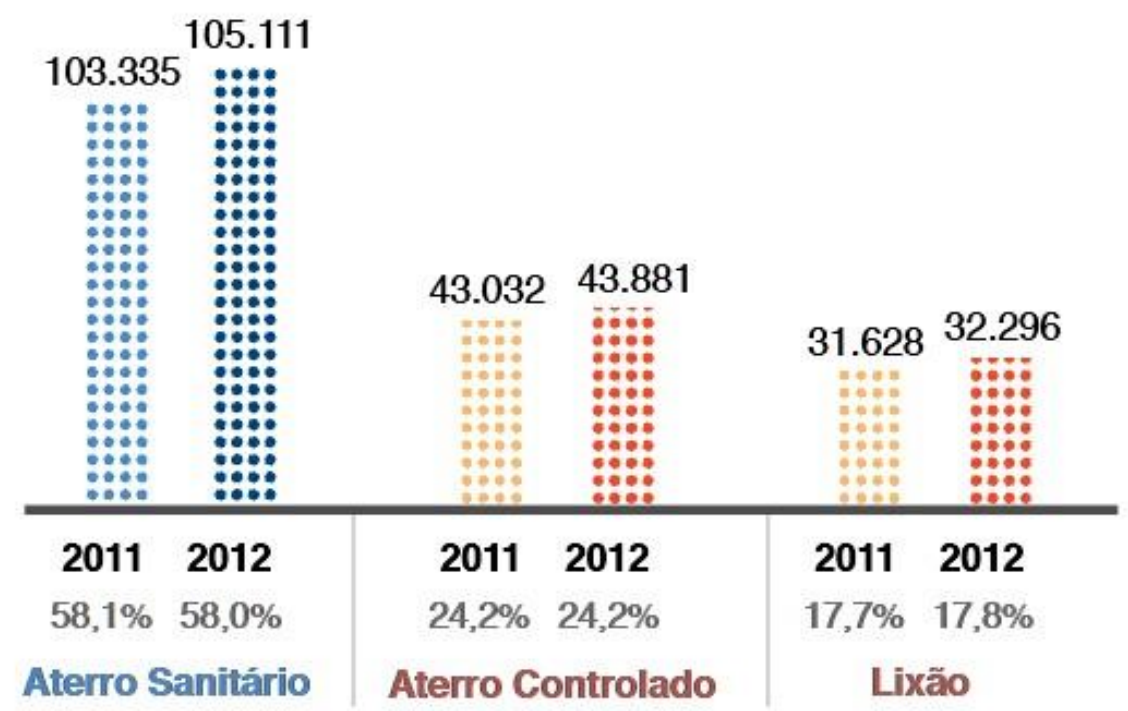

Fig. 2 - Destinação final de RSU (t/dia)

(Fonte: Pesquisa ABRELPE,2012) 
$\mathrm{Na}$ figura pode ser observado que apesar da deposição em aterros sanitários apresentarse como a maior quantidade de dispor os resíduos sólidos as outras opções ainda são tidas como saídas, não cessando o crescimento de aterros controlados e lixões. A área de estudo focou-se na deposição de resíduos em área de aterro controlado que apesar de ter medidas de controle de poluição algo que os lixões não apresentam, deixam muitos aspectos a desejar como a permissão de acesso de pessoas e de animais.

\section{Área de Estudo}

O presente estudo foi realizado no Aterro Controlado de Gericinó, em operação desde 1988 no bairro de Bangú, localizado na Zona Oeste do município do Rio de Janeiro.

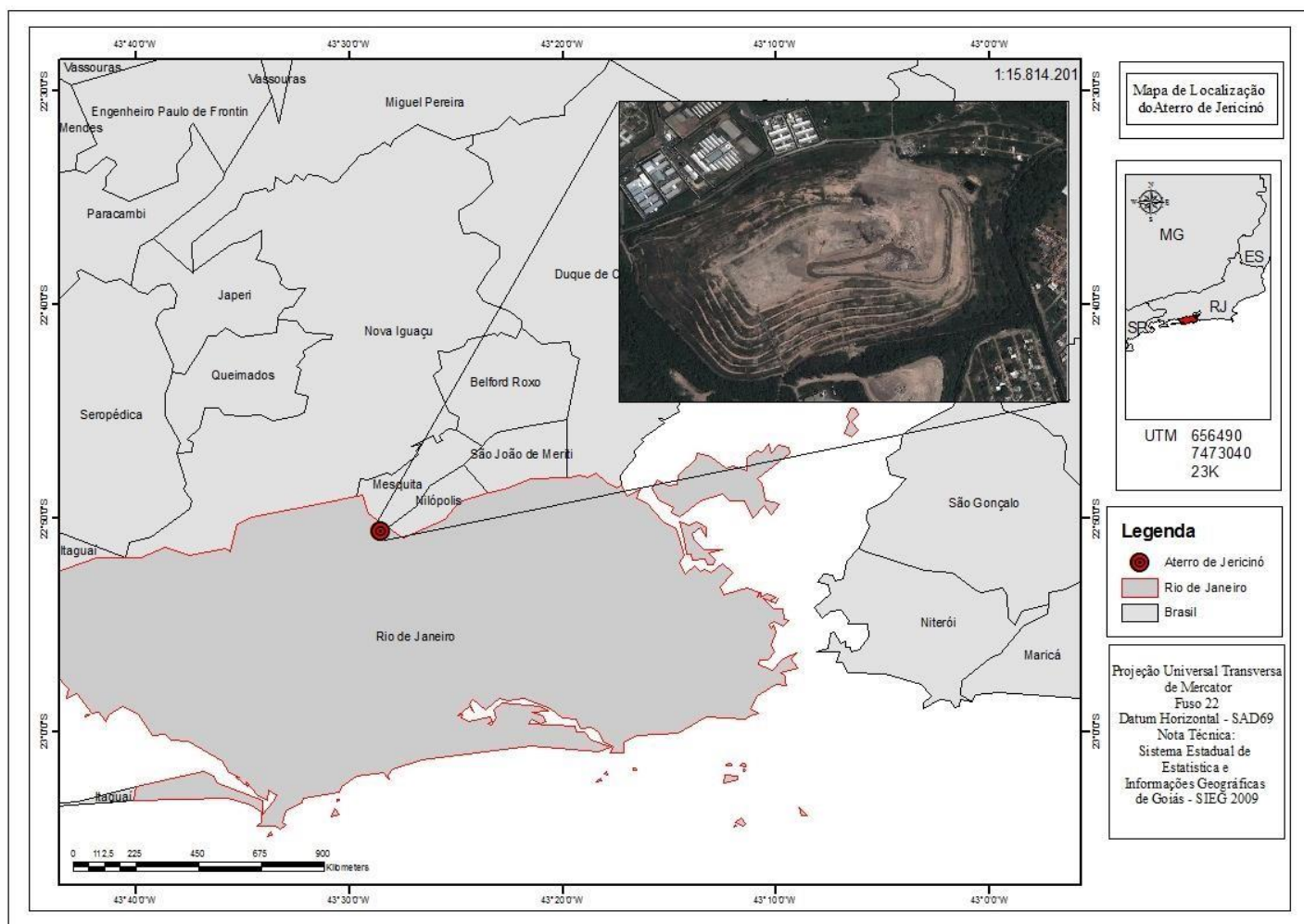

Fig. 3 - Mapa de localização do Aterro Controlado de Gericinó.

Antigo vazadouro (também chamado de "lixão a céu aberto"), o local, apesar da mudança da estrutura que o transformou em aterro controlado, continua a ser fonte de sustento e trabalho para inúmeras famílias de catadores. Tal prática, remanescente do anterior modelo de deposição de resíduos sólidos, pôde ser observada na visita de campo realizada em novembro de 2013, donde se registrou a fotografia a seguir. 


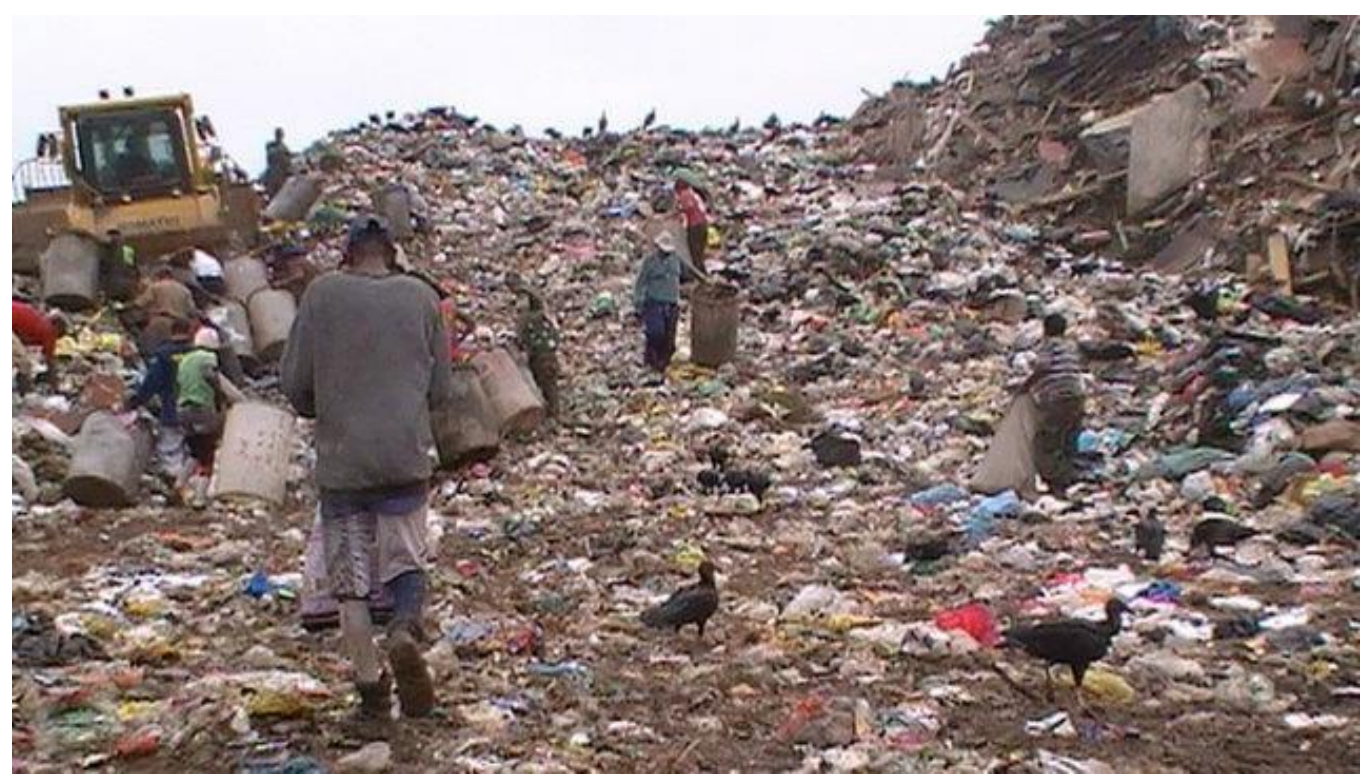

Fig. 4 - Situação dos catadores no aterro controlado de Gericinó.

(Fonte: Clarice Lima, 2013)

Segundo dados da Companhia Municipal de Limpeza Urbana do Rio de Janeiro COMLURB (2013), o Aterro de Gericinó recebe cotidianamente cerca de 240 catadores, cuja fonte de renda é extraída das (aproximadas) três mil toneladas de rejeitos domésticos e entulhos $^{2}$ que são coletados diariamente nas zonas norte e oeste da cidade ${ }^{3}$.

Os catadores possuem crachás e coletes de identificação, sendo ainda acompanhados por um assistente social. Apesar dos riscos sociais e sanitários da atividade, a flexibilidade de horário no trabalho dentro do sistema de catação somada à facilidade de ganhos (um catador pode lucrar, em média, até $\mathrm{R}$ \$ 200,00/dia) são fatores que têm dificultado a organização e regulamentação da classe enquanto categoria profissional (exemplo disto são as complicações encontradas para a constituição de associações ou cooperativas).

Falta, pois, perspectiva quanto à profissionalização da categoria e à normatização do setor, o que implicaria na instituição de políticas públicas voltadas para pensar de forma integrada a gestão do lixo e a inclusão social dos sujeitos a ele diretamente vinculados. Enquanto isso, junto à degradação do ambiente natural insere-se também a degradação do

\footnotetext{
${ }^{2}$ Esse valor oscila para mais nos dias de segunda e terça em função da redução das atividades de coleta nos finais de semanas.

${ }^{3}$ Não está inclusa aí a coleta dos resíduos provenientes dos bairros de Jacarepaguá e Barra da Tijuca, que são depositados no aterro sanitário de Seropédicaa
} 
ambiente humano, em um contexto no qual as condições dignas de sobrevivência e a qualidade de vida inexistem para esses trabalhadores. Vivendo do lixo, eles são levados a correr, todos os dias, em tempo de chuva ou sol, atrás dos caminhões de coleta, disputando com animais silvestres e domésticos um espaço sanitário precário, sem qualquer segurança ${ }^{4}$, colocando, assim, em risco suas vidas e saúde.

Em depoimento conseguido por uma Jovem catadora, Luana, 25 anos, através da visita de campo ao aterro controlado de Gericinó, esta diz:

\begin{abstract}
"Eu e minha mãe trabalhos aqui, minha mãe desde que eu era pequena, oito anos... Meu objetivo não é de ficar aqui toda vida, pois isso vicia muito por você arrumar dinheiro rápido, quero ano que vem prestar um concurso público porque quero ser psicóloga, seguir outra vida porque aqui a vida é muito sofrida trabalhamos em sol, chuva, poeira e às vezes se adoece não tem nenhum seguro de vida... Fechar aterros e lixões é um pouco triste porque isso aqui já ajudou muita gente, pessoas da comunidade que ficam desempregadas vêm para cá, pois muitos têm família e aluguel para pagar...".
\end{abstract}

Permitir o acesso de catadores em locais de deposição de resíduos colabora para perpetuação de um trabalho indigno, impróprio para as condições de vida humana deixando estes em situação de vulnerabilidade social por estar em área com potencial de risco a saúde. Verifica-se, assim, a necessidade de encerrar lixões e aterros controlados, com acompanhamento de especialistas aos catadores e cursos de capacitação, para que estes sejam e sintam-se motivados a trabalhar em cooperativas ou associações de catadores, tendo um trabalho mais digno, em local salubre e organizado.

A necessidade de medidas urgentes que busquem uma solução para famílias que se sustentam da catação de lixo em lixões e aterros controlados se torna cada vez mais necessária, pois, com o advento da Política Nacional de Resíduos Sólidos através da Lei 12.305/2010, busca-se a desativação dos mesmos, restando como forma de disposição final os aterros sanitários que não permite acesso da população, logo, acabando com o sistema de catação diretamente no lixo.

$\mathrm{O}$ aterro controlado de Gericinó que possui previsão de fechamento ainda no ano de 2014, tem como proposta à reconstrução da vida dos catadores após o fechamento do aterro, por parte da prefeitura do Rio de Janeiro, receber um fundo de capacitação no valor de $\mathrm{R} \$ 13,9$

\footnotetext{
${ }^{4}$ Em geral, os catadores entram em contato direto com o lixo sem utilizar, pois, qualquer equipamento de proteção. Isto propicia, dada às condições insalubres dos aterros, acidentes de trabalho e contaminações diversas por meio dos vetores transmissores de doenças que se se proliferam nesse tipo de lugar. Falta, entretanto, pesquisa mais aprofundada e informações mais consistentes sobre o assunto.
} 
mil, por meio do Serviço Social da Indústria do Rio de Janeiro (SESI - RJ) pela ministração de cursos no local de cozinheiro, eletricista, camareiro e promover a alfabetização dos adultos.

Porém, além dos cursos de capacitação que pretendem serem oferecidos visando outras formas de trabalho, estes precisam de uma maior reestruturação do sistema de limpeza urbana com elaboração de políticas públicas eficientes e uma gestão integrada dos resíduos sólidos se pretenderem continuar da catação como será especificado na parte de mitigação aos impactos.

\section{Mitigação aos Impactos}

A solução ao problema de indivíduos que trabalham catando em montanha de lixo, correndo riscos de vida e saúde, seria dar a destinação adequada aos resíduos sólidos, por meio de um sistema de gestão que seja eficiente e sustentável, o da gestão integrada de resíduos sólidos.

A gestão integrada coopera na atuação de ações que visam solucionar a questão dos resíduos sólidos, juntando os diferentes atores da sociedade civil às esferas políticas, econômicas, ambientais, culturais, sociais e a mídia focando no desenvolvimento sustentável, visando uma redução na geração dos resíduos, aumento no seu reuso e reciclagem, e geração de emprego e renda com qualidade de vida.

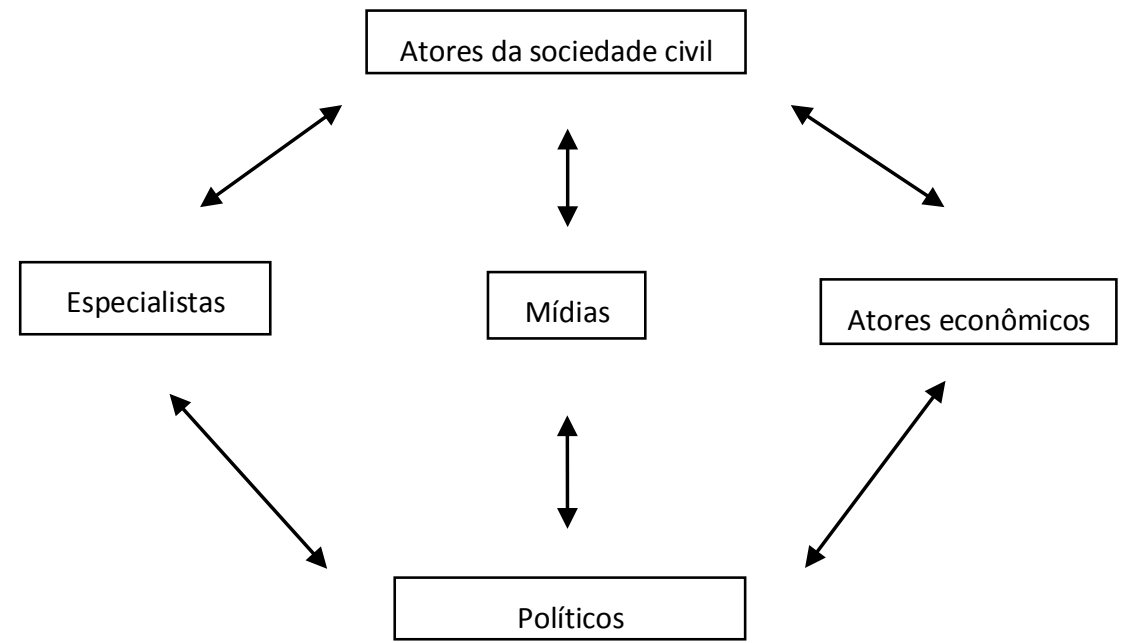

Fig. 5 - A intervenção dos atores da sociedade civil

(Fonte: Os riscos - o homem como agressor e vítima do meio ambiente. Yvette Veyret, 2007) 
Dentre os atores da sociedade civil, os especialistas deveriam estar divididos em quatro categorias, desempenhando cada um diferentes funções colaborando com o desempenho do trabalho dos catadores:

- os especialistas ambientais - aconselhar e guiar o poder público na tomada de decisões que visem um equilíbrio com a diminuição de vulnerabilidades entre o homem e o meio natural;

- especialistas sociais - promover a reintegração social da parcela de excluídos, por meio de trabalho que promova sua absorção desses dentro da sociedade;

- especialistas da saúde - médicos e psicólogos, para realizar o acompanhamento dos sujeitos que trabalham em áreas com risco por contaminação;

- especialistas da área jurídica - defender o direito dos trabalhadores e colaborar na formação do sindicato de catadores;

Os políticos têm por objetivo desempenhar o papel de elaboração de políticas públicas que tratem de implementar, estruturar e executar a gestão dos resíduos sólidos, exigindo dos cidadãos e do setores empresariais e industriais uma participação mais ativa no que tange à separação dos materiais para a coleta seletiva; e ainda, no caso destes últimos, cobrar e fiscalizar suas iniciativas de responsabilidade socioambiental, favorecendo parcerias públicoprivadas de incentivo à cooperativas ou associações de catadores.

A mídia, utilizada para divulgar em grande escala a necessidade de reduzir, reutilizar e reciclar o lixo, através da conscientização da população com o uso da educação ambiental, por meio de campanhas e propagandas socioeducativas.

Só poderemos falar em uma efetivação da coleta seletiva, sistema que tem como base a colaboração social, conforme observação criteriosa das variáveis anteriormente enumeradas. A coleta seletiva é, neste sentido, essencial ao desenvolvimento sustentável do meio urbano na medida em que alcança as esferas econômicas, sociais e ambientais, tendo por apoio estratégias que visam primeiramente à redução do consumo e geração de resíduos respaldados na reutilização. Ela fecha, de forma gradual e sistêmica, o círculo da problemática dos resíduos sólidos urbanos uma vez que a sua prática tem como princípio reduzir o volume dos resíduos descartados como rejeitos, poupando, assim, por meio da reciclagem, a extração de novos recursos naturais para a produção de bens de consumo (SALDIVA et al., 2010).

A construção do sistema de coleta seletiva no meio urbano necessita da implantação de cooperativas/associação de catadores como opção de renda digna aos trabalhadores que vivem 
da exploração econômica do lixo. Na cadeia da coleta seletiva, eles terão como papel realizar o beneficiamento primário ${ }^{5}$ dos materiais que foram pré-separados nas fontes geradoras (residências, departamentos comerciais e governamentais e indústrias).

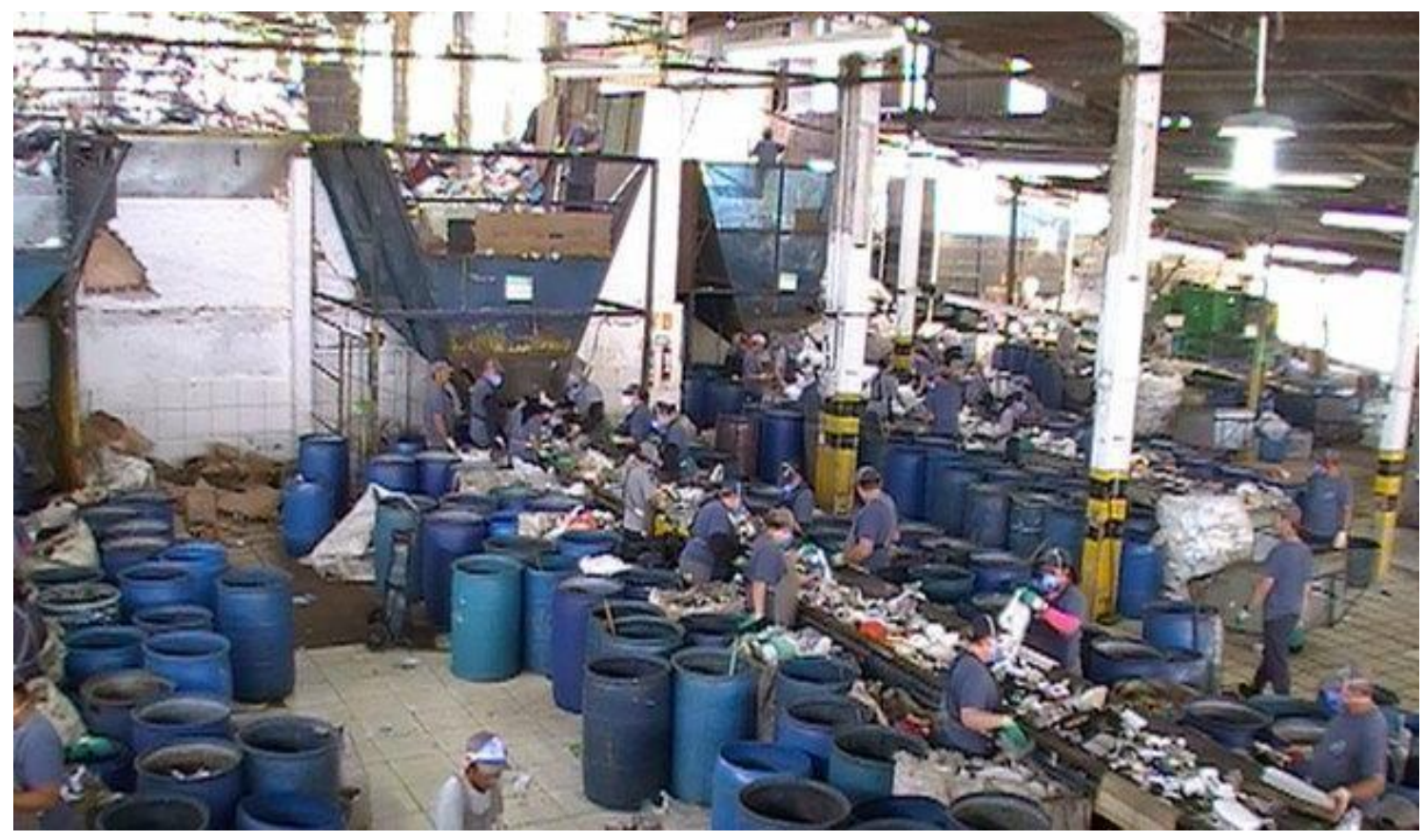

Fig. 6 - Catação na Unidade de Valoração de Resíduos, Curitiba. (Fonte: Clarice Lima, 2013)

Assim, apenas o que é rejeito será destinado para aterros sanitários, diminuindo a quantidade de resíduos transportados a esse diariamente, aumento seu tempo de vida útil, diminuindo o desperdício de recursos naturais, e colaborando para o desenvolvimento sustentável em sociedade.

Sachs (2007) traz desenvolvimento sustentável como forma de conter a produção humana, estando sustentada no tripé dos princípios de utilidade social, viabilidade econômica e prudência ecológica. O ordenamento desses três princípios gera uma nova forma de produção, primando pelo valor social, às restrições ecológicas e o reposicionamento da economia como um instrumento de produção utilizado pela sociedade para saciar principalmente as suas necessidades básicas.

\footnotetext{
${ }^{5} \mathrm{O}$ beneficiamento primário na etapa de triagem trata da separação dos materiais por tipo e/ou cor (plástico branco ou verde; papel branco ou colorido; plástico duro ou mole; pet; vidro; latinhas) e o seu enfardamento para serem posteriormente comercializados. Essa separação é executada por catadores ou empregados comuns, que separam os materiais em tambores, pesando-as e recebendo de acordo com o quilo estipulado para cada material.
} 


\section{CONSIDERAÇÕES FINAIS}

Com este artigo fica evidenciada a necessidade de uma boa gestão dos resíduos sólidos, pois, a má gestão desses geram riscos para o meio ambiente e social. Na parte de mitigação de impactos deste trabalho a estrutura exposta visa minimizar os riscos dos resíduos para população e inclusive aos indivíduos que fazem uso deste meio como sustento.

Destaca-se que a utilização da educação ambiental é necessária para modificação dos sistemas de gestão dos resíduos sólidos, pois este para ser sustentável necessita da implantação de sistema de coleta seletiva, esta que requer a colaboração da população, que somente podem contribuir com o sistema através do conhecimento, praticando-o e realizando cobranças quanto às ações que competem ao poder público.

\section{REFERENCIAS}

ABRELPE, Panorama dos Resíduos Sólidos no Brasil. São Paulo, 2012.

BORGATTO, André Vinícius Azevedo. Estudo das Propriedades Geomecânicas de Resíduos Sólidos Urbanos Pré-tratados. Dissertação (Mestrado em Engenharia Civil). - COPPE, Universidade Federal do Rio de Janeiro, Rio de Janeiro, 2010.

CALDERONI, Sabetai. Os Bilhões Perdidos no Lixo. $3^{\text {a }}$ ed. São Paulo: Humanitás Livraria/FFLCH/USP; 1999.

CARPI JÚNIOR, Salvador. Processos Erosivos, Riscos Ambientais e Recursos Hídricos na Bacia do Rio Mogi-Guaçu. Tese (Doutorado em Geociências e Meio Ambiente) - Instituto de Geociências e Ciências Exatas, Universidade Estadual Paulista, Rio Claro, SP, 2001.

COMLURB. Aterro Controlado de Gericinó. Rio de Janeiro, 2013.

CUNHA, Janice Machado; et al. A Vulnerabilidade Social no Contexto Metropolitano: O Caso de Campinas. In: ENCONTRO ANUAL DA ANPOCS, 27.Caxambu. Anais, 2003.

DAGNINO, Ricardo de Sampaio; CAPRI, Salvador Júnior. Risco Ambiental: Conceitos e Aplicações. CLIMEP - Climatologia e Estudos da Paisagem, Rio Claro/SP, 2007. Disponível em:

<http://www.periodicos.rc.biblioteca.unesp.br/index.php/climatologia/article/view/1026/958> . Acessado em: 17 de agosto 2013.

DANTAS, Katia Monte Chiari. Proposição e Avaliação de Sistemas de Gestão Ambiental 
Integrada de Resíduos Sólidos Através de Indicadores em Municípios do Rio de Janeiro. Tese (Doutorado em Engenharia Civil), Universidade Federal do Rio de Janeiro. Rio de Janeiro, 2008.

ESCOREL, Sarah et al. A Construção do Sócio-Ambiente Insustentável. In: SEMINÁRIO NACIONAL DE SAÚDE E AMBIENTE NO PROCESSO DE DESENVOLVIMENTO, 1. 2000, Rio de Janeiro. Eventos científicos 2. Rio de Janeiro, 2000. p. 111-126.

FUNASA. Resíduos Sólidos e a Saúde da Comunidade: Informações Técnicas Sobre a Interrelação Saúde, Meio Ambiente e Resíduos Sólidos /Fundação Nacional de Saúde. Brasília, 2013.

HOGAN, Daniel Joseph; et al. Urbanização e Vulnerabilidades Sócio-Ambientais Diferenciadas: o caso de Campinas. In: ENCONTRO NACIONAL DE ESTUDOS POPULACIONAIS, 12. 2000, Caxambu. Anais. Caxambu: ABEP, 2000. Disponível em: <http://www.abep.nepo.unicamp.br/docs/anais/pdf/2000/todos/ambt15_2.pdf>. Acesso em: 18 de agosto 2013.

LIMA, José Mario de Queiroz. Tratamento de Lixo. Editora Hemus LTDA, 2a Edição. São Paulo-SP, 1991.

MENDONÇA, Francisco. (Org.). Impactos Socioambientais Urbanos. Curitiba: Ed. UFPR, 2004.

REBELO, Fernando. Riscos Naturais e Acção Antrópica. Coimbra: Imprensa da Universidade, 2003.

RIBEIRO, Túlio Franco; LIMA, Samuel Carmo. Coleta Seletiva de Lixo Domiciliar - Estudos de Caso. Caminhos de Geografia: Programa de Pós Graduação em Geografia, Uberlândia, p.50-69, 2000.

RODRIGUES, Arlete Moysés. Produção do Espaço e Ambiente Urbano. In: SPOSITO, M. E. B. (Org.) Urbanização e cidades: perspectivas geográficas. Presidente Prudente: UNESP/FCT, 2001, p.211-30.

SACHS, Ignacy. Rumo à Ecossocioeconomia: Teoria e Prática do Desenvolvimento. Organização de Paulo Freire Vieira. São Paulo: Cortez, 2007, passim.

SEVÁ FILHO, Oswaldo. No Limite dos Riscos e da Dominação: A Politização dos Investimentos Industriais de Grande Porte. Tese (Livre-Docência) - Instituto de Geociências, Universidade Estadual de Campinas, Campinas, SP, 1998.

VEYRET, Yvette; MESCHINET DE RICHEMOND, Nancy. O Risco, os Riscos. In: VEYRET, Y. (Org.) Os Riscos - o Homem como agressor e vítima do meio ambiente. São Paulo: Contexto, 2007.

VIEILLARD-BARON, H. (2007), Os Riscos sociais. In: VEYRET, Y. (Org.) Os Riscos: o homem como agressor e vítima do meio ambiente. São Paulo: Contexto. 